\title{
Chronic lymphocytic leukaemia trends and features at a tertiary hospital in South Africa (2011-2016)
}

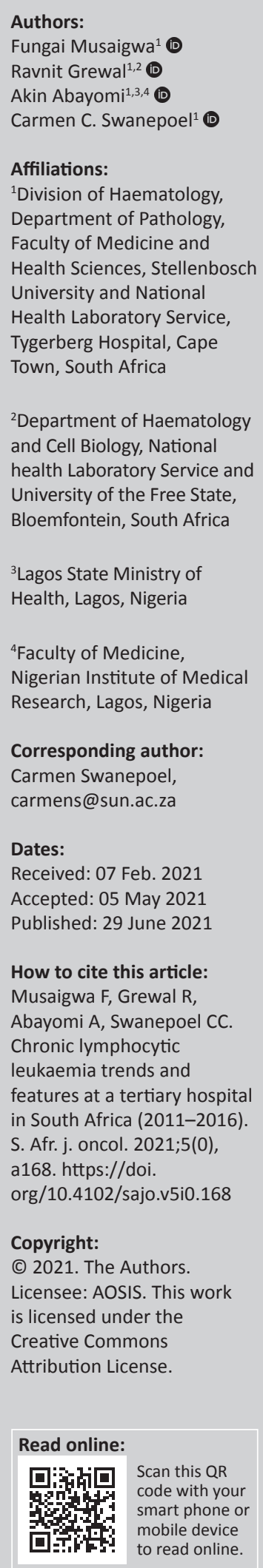

Background: Chronic lymphocytic leukaemia (CLL) is a common lymphoproliferative disorder in developed countries. However, this condition is rare in Africa and there is a paucity of information on CLL, specifically on the continent.

Aim: This study described, retrospectively, the frequency, demographics and laboratory features of CLL cases diagnosed from 2011 to 2016.

Setting: Department of Pathology, National Health Laboratory Service, Tygerberg Academic Hospital, Cape Town.

Methods: A retrospective analysis was performed for all CLL diagnoses made between 01 January 2011 and 31 December 2016.

Results: Eighty CLL cases were diagnosed between 2011 and 2016. Men and women presented with the disease equally $(48.8 \%$ vs. $51.2 \%, p>0.05)$. The mean age at diagnosis was 66.79 years (range of 37-95 years) and the modal age range (36.3\%) was 60-69 years. Men presented with the disease at a significantly younger age than women (mean $=64$ years vs. mean $=69.5$ years, $p<0.05)$. There were three $(3.75 \%)$ human immunodeficiency virus (HIV)-positive patients (age range $43-50$ years). Chromosome 13q14 deletion was found in 6 out of 19 patients (31.6\%). Trisomy 12 and deletion 11q22 were found in 5 out of $21(24 \%)$ and 7 out of 21 (33.3\%) patients, respectively. Deletions 13q34 and 17p were negative for 6 and 20 patients, respectively.

Conclusion: Chronic lymphocytic leukaemia at our facility presented equally in men and women. Men presented with the disease at a younger age than women. Additionally, our findings suggested that HIV is uncommon amongst CLL patients tested for HIV.

Keywords: chronic lymphocytic leukaemia; CLL; diagnosis; incidence; cytogenetics; HIV.

\section{Background}

Chronic lymphocytic leukaemia (CLL) is a clonal lymphoproliferative disorder of B-cells that have a deregulated programmed cell death (apoptosis). ${ }^{1,2,3}$ The malignancy has a variable course, with some patients requiring only supportive treatment with long-term survival, whereas others are burdened with progressive disease associated with commonly fatal complications. ${ }^{4,5}$

Representing the most common leukaemia in the Western countries, CLL has an estimated incidence rate falling between less than 1 and 5.5 per 100000 population, an average age range of 64-72 years at diagnosis, and is more common in men. $5,6,7,8$

The majority of CLL cases are diagnosed during routine blood analysis in otherwise asymptomatic patients. Less commonly, CLL is diagnosed in patients who present with lymphadenopathy, splenomegaly, anaemia and/or thrombocytopenia. ${ }^{9}$ The diagnosis is made when the patient has a persistent lymphocytosis of greater than $5 \times 10^{9}$ B-cells/L of mature lymphocytes in the peripheral blood and often in the absence of disease-related symptoms or tissue involvement other than bone marrow., ${ }^{90,11}$ The identification and characterisation of abnormal lymphocytes from normal and reactive cells are crucial steps to final diagnosis. Aberrant lymphocytes can be clearly distinguished from normal and reactive lymphocytes by morphology and immunophenotyping. ${ }^{., 10,12}$

Morphological examination of peripheral blood by microscopy, the World Health Organization (WHO) gold standard, is commonly the first step in the pathologic evaluation of suspected CLL disease. ${ }^{13}$ The cells in typical CLL are small lymphocytes with a high nucleocytoplasmic ratio and clumped nuclei with inconspicuous nucleoli. Additionally, smudge cells or basket cells are present on the peripheral blood smear and the bone marrow aspirate smear.9,10,12,14 To aid in the 
confirmation of the diagnosis, morphologically suspected cases of CLL are further evaluated by immunohistochemistry and flow cytometry immunophenotyping. Typical CLL cells are monoclonal and express cluster of differentiation (CD)19, CD20, CD22 and CD79b with dim surface immunoglobulin (Ig) M/D. In addition, the cells co-express CD5, CD19 and CD23, are strongly positive for CD200, negative for CD10 and are negative or weakly positive for FMC7.9,10,11,12,14,15,16 Furthermore, the evaluation of cytogenetic abnormalities can be useful in differential diagnoses,, 12 prognostic evaluations and treatment planning. 5,9,11,17

Common structural abnormalities of chromosomes in CLL are the deletion of short arm of chromosome 17 (deletion 17p), deletion of long arm of chromosome 11 (deletion 11q), deletion of long arm of chromosome 13 (deletion 13q) and trisomy of chromosome 12 (trisomy 12). At least one of these chromosomal alterations is identified in an estimated $80 \%$ of CLL patients. ${ }^{5,9,17}$ Deletion 17p is associated with an unfavourable clinical course and the abnormality often indicates the loss of the tumour suppressor gene TP53, whose mutation status is critical in choosing a treatment strategy $y^{5,9,17}$. Similarly, deletion 11q, which signals alterations in the deoxyribonucleic acid (DNA) (deoxyribonucleic acid) repairment-associated ATM (ataxiatelangiectasia mutated) gene, is also associated with a poor clinical course. ${ }^{5,9,17}$ On the other hand, deletion $13 q$ generally confers a favourable clinical outcome, ${ }^{9}$ whilst trisomy 12 is associated with an intermediate clinical outcome. ${ }^{5}$ However, the majority of these molecular data are representative of Western countries because there is a paucity in African-specific CLL cytogenetic information.

In Africa, CLL has been described as a rare occurrence. ${ }^{18}$ However, CLL-specific information in African countries is scarce. Clinical and laboratory studies exploring diagnostic demographics, prognostic patterns and cytogenetic abnormalities associated with CLL in Africa are limited..$^{18}$ A study conducted by Nel et al, over two decades ago, confirmed that the clinical presentation of CLL in South Africa (SA) is similar to that of the rest of the world. ${ }^{19}$ Likewise, CLL presentation in Nigeria was reported to be similar to the rest of the world, although with a relatively shorter survival period in comparison to developed countries. ${ }^{20}$ In Senegal, CLL has been shown to be more aggressive with a worse prognosis at a younger age than in developed countries. ${ }^{18}$ These variable reports from smallscale African studies necessitate the need for large-scale epidemiological studies in African countries. One way of capturing such large cancer data is through nationwide cancer surveillance tools such as national registries. In SA, the National Cancer Registry (NCR) facilitates the nationwide surveillance of cancer. The cancer entities, however, are often grouped together despite their different management strategies. As such, there is a lack of critical cancer entity-specific information pertaining to specific cancers such as CLL in SA, and Africa at large. Hence, we evaluated within the present study the presentation of CLL, specifically its demographics, diagnostic patterns and its associated cytogenetic abnormalities at a selected teaching hospital in the Western Cape province of SA.

\section{Methods Study design}

A retrospective analytical study was performed for all CLL diagnoses made within the Divisions of Anatomical Pathology and Hematopathology, Department of Pathology, National Health Laboratory Service (NHLS), Tygerberg Academic Hospital (TAH), SA. Tygerberg Academic Hospital is one of the largest tertiary referral academic hospitals in SA with a catchment population of approximately 2.5 million. ${ }^{21,22,23}$ The hospital provides specialist haematology care to the population of the Western Cape province and surrounding catchment areas and leukaemia diagnoses are made at the hospital.

\section{Participant selection}

The results of all patients diagnosed with CLL at TAH were captured from two routine laboratory data management software packages, the DISA (DisaLab version 04.16.04.814, Laboratory System Technologies, Johannesburg, SA) for the years 2011-2015 and the TrakCare laboratory information systems (L6.10, InterSystems Corporation, Cambridge, MA, United States [US]) for the years 2015-2016. The leukaemia diagnoses that were established and subtyped to identify CLL in the NHLS TAH unit were performed using the $2008 \mathrm{WHO}$ classification of tumours of haematopoietic and lymphoid organs guidelines ${ }^{24}$ by qualified pathologists and clinicians. The diagnostic process at TAH involved investigations on the patient's full blood counts. In addition, morphological examinations of peripheral blood films under a microscope were conducted followed by flow cytometry immunophenotyping and cytogenetic evaluations prior to treatment. These confirmed diagnoses were reviewed to collect data on demographic characteristics (age and gender), clinical features, de-identified place of primary residence, date of diagnosis, human immunodeficiency virus (HIV) status (tested using enzymelinked immunosorbent assay HIV serology) and cytogenetic properties (tested using fluorescence in situ hybridization [FISH] and/or karyotyping). Collectively, all CLL cases diagnosed between 01 January 2011 and 31 December 2016 were reviewed and included in the study, summing up to a total of six years. In some instances, patients from other provinces were referred to the tertiary hospital for diagnosis because of its improved healthcare systems. ${ }^{23}$ Efforts were made to exclude these referral cases from our study because they did not represent our target population of the Western Cape Province, SA, the true catchment area of the TAH. In addition, patients who presented with relapses were also excluded from the study.

\section{Data analysis}

All statistical analyses were performed in consultation with a biostatistician using Microsoft Excel ${ }^{\circledR}$ software and International Business Machines Corporation Statistical Package for the Social Sciences (IBM SPSS) software for Windows, version 26 (SPSS Inc., Chicago, IL, US). Descriptive 
statistics were used to analyse data by age, gender, HIV status and cytogenetic properties. Data normality was tested using the Shapiro-Wilk test and the two-tailed independent $t$-test was used to describe age patterns of gender-grouped participants. The likelihood ratio chi-square test was used to describe gender frequencies at diagnosis. All statistical tests were performed at $95 \%$ confidence interval (CI) and a $p$-value of less than 0.05 was regarded as significant.

\section{Results}

\section{Yearly diagnoses}

There were 80 absolute cases of CLL diagnosed at TAH between the years 2011 and 2016 (Table 1). The frequencies of CLL cases diagnosed followed an irregular annual pattern with no clear trend (Figure 1). There was a small increase of cases between the years 2011 and 2012, which was followed by a decrease in the year 2013 . The cases increased in the year 2014, which represented the highest number of cases over the study period. Thereafter, there was a decline of cases for the years 2014-2016 (Figure 1).

\section{Gender and age}

Women (51.2\%) presented with CLL more than men (48.8\%) at TAH. However, statistical analyses showed an equal distribution of the genders at CLL presentation over the

TABLE 1: Characteristics of newly diagnosed chronic lymphocytic leukaemia cases at TAH, 2011-2016.

\begin{tabular}{|c|c|c|c|c|c|c|c|}
\hline \multirow[t]{2}{*}{ Characteristics } & \multirow[t]{2}{*}{ Age } & \multirow{2}{*}{$\begin{array}{l}\text { No. tested } \\
(n)\end{array}$} & \multirow[t]{2}{*}{$\bar{p}$} & \multicolumn{2}{|c|}{ Total patients $(n=80)$} & \multirow[t]{2}{*}{ Mean } & \multirow[t]{2}{*}{ s.d. } \\
\hline & & & & $n$ & $\%$ & & \\
\hline \multicolumn{8}{|l|}{ Gender } \\
\hline Men & - & - & 0.56 & 39 & 48.80 & - & - \\
\hline Women & - & - & - & 41 & 51.20 & - & - \\
\hline \multicolumn{8}{|l|}{$\begin{array}{l}\text { Age summary } \\
\text { (years) }\end{array}$} \\
\hline Mean & - & - & - & - & - & 66.79 & - \\
\hline Interquartile range & $60-74$ & - & - & - & - & - & - \\
\hline Range & $37-95$ & - & - & - & - & - & - \\
\hline Men & - & - & $0.03 *$ & - & - & 63.97 & 10.45 \\
\hline Women & - & - & - & - & - & 69.46 & 11.77 \\
\hline \multicolumn{8}{|l|}{$\begin{array}{l}\text { Age categories } \\
\text { (years) }\end{array}$} \\
\hline$<40$ & - & - & - & 1 & 1.25 & - & - \\
\hline $40-49$ & - & - & - & 6 & 7.50 & - & - \\
\hline $50-59$ & - & - & - & 13 & 16.25 & - & - \\
\hline $60-69$ & - & - & - & 29 & 36.25 & - & - \\
\hline 70-79 & - & - & - & 17 & 21.25 & - & - \\
\hline $80-89$ & - & - & - & 13 & 16.25 & - & - \\
\hline $90+$ & - & - & - & 1 & 1.25 & - & - \\
\hline HIV status & - & 43 & - & - & - & - & - \\
\hline Negative & - & - & - & 40 & 50.00 & - & - \\
\hline Positive & - & - & - & 3 & 3.75 & - & - \\
\hline Unknown & - & - & - & 37 & 46.25 & - & - \\
\hline \multicolumn{8}{|l|}{ Cytogenetics } \\
\hline Deletion 13q14 & - & 19 & - & 6 & 31.60 & - & - \\
\hline Deletion $13 q 34$ & - & 6 & - & 0 & 0.00 & - & - \\
\hline Trisomy 12 & - & 21 & - & 7 & 33.30 & - & - \\
\hline Deletion $11 q 22$ & - & 20 & - & 4 & 20.00 & - & - \\
\hline Deletion 17p13 & - & 20 & - & 0 & 0.00 & - & - \\
\hline
\end{tabular}

s.d., standard deviation.

$*, p<0.05$.
6 -year period $(p>0.05)$. The age of patients diagnosed with CLL ranged from 37 to 95 years. The mean age of CLL diagnosis at TAH was 66.79 years (Table 1 ). The modal age at diagnosis (36.25\%) was in the range of 60-69 years (Table 1 and Figure 2). Men (mean age $=63.97$ years) presented with the disease at a significantly younger age than women (mean age $=69.46$ years) (Table 1 and Figure 2$)(p<0.05)$.

\section{Human immunodeficiency virus}

Confirmed HIV test results were available for 53.75\% (43/80) of CLL patients in our study (Table 1). There were no confirmed HIV test results for the remaining 46.25\% (37/80) of the CLL patients. Altogether, 3.75\% (3/80) of the patients, which represented $6.98 \%(3 / 43)$ of confirmed HIV statuses, were HIV-positive. Of those with confirmed HIV test results, $93.02 \%(40 / 43)$ of patients were negative. In addition, $81.08 \%$ $(30 / 37)$ of CLL patients with unavailable HIV test results were aged 65 years and older. Noteworthily, HIV-positive patients had CLL disease with typical morphologic and immunophenotypic features that were similar to those of HIV-negative patients.

\section{Cytogenetic profiling}

Only 37\% (30/80) of patients were found to have been tested for cytogenetic abnormalities in our study. Deletion 13q14

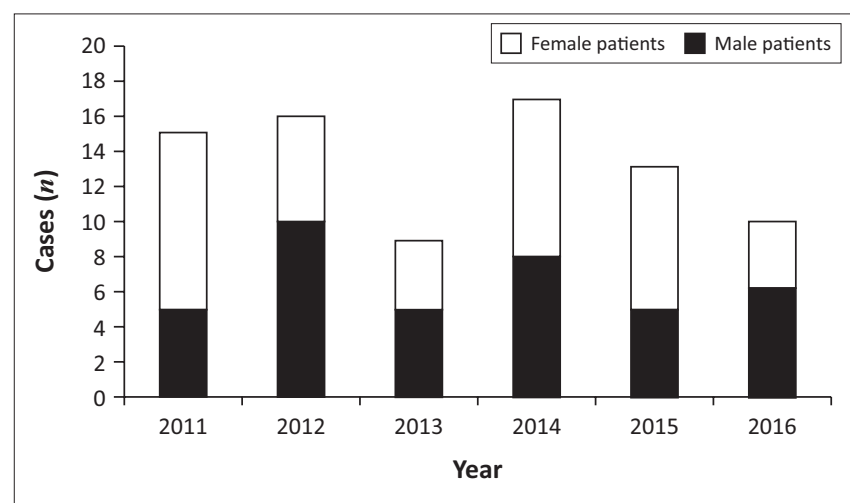

FIGURE 1: Number of incident chronic lymphocytic leukaemia cases by year and gender, 2011-2016.

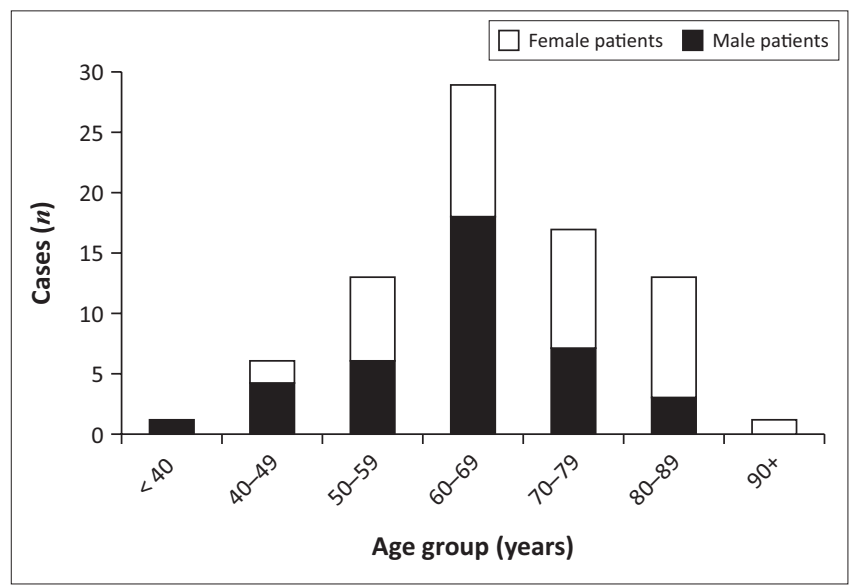

FIGURE 2: Distribution of chronic lymphocytic leukaemia cases by age group and gender, 2011-2016. 
was found in $31.6 \%(6 / 19)$ of patients. Trisomy 12 and deletion 11q22 were found in 33.3\% (7/21) and 20\% (4/20) of patients, respectively. Interestingly, two patients, an HIVpositive female aged 50 years and an HIV-negative male aged 57 years carried both trisomy 12 and the 11q22. Deletions 17 p13 and 13q34 were tested for in 20 and 7 patients, respectively, and all were negative.

\section{Discussion}

\section{Yearly diagnoses}

The frequency of CLL cases that were diagnosed at TAH followed a variable yearly pattern with no clear one-sided trend (Figure 1). In developing African countries, CLL occurrence has been described as low. ${ }^{25}$ However, in developing African countries, large-scale CLL surveillance data are often not easily accessible, may be largely unavailable and/or may be grouped with no clear separation of cancer subtypes. Furthermore, the accurate diagnosis of the disease in African countries has previously been highlighted as a possible major shortcoming because of limited diagnostic resources in some areas. ${ }^{4}$ As such, observations made on occurrences of CLL in developing African countries may be underestimated. In our case, however, TAH is fully equipped with resources to accurately diagnose CLL with precision. Nevertheless, efforts to quantify CLL diagnoses at a large scale in SA remain limited by sub-optimal cancer surveillance tools. Clearly, further studies and optimal cancer surveillance tools are warranted to improve our understanding of the CLL burden in SA and Africa at large.

\section{Gender and age}

Our findings highlight a generally equal representation of women and men during CLL diagnosis at TAH (Table 1). In contrast, more women than men have been shown to present with the disease in other African countries such as Zambia ${ }^{26}$ and Nigeria, $, 420,27,28$ whilst more men than women were reported in SA, ${ }^{19}$ Morocco, ${ }^{29}$ Zimbabwe and Malawi, ${ }^{30}$ Senegal, ${ }^{18}$ Kenya $^{31}$ and Algeria. ${ }^{32}$ In addition, our observations differ from reports of developed countries where CLL occurrence is higher in men. $5,6,7,8,33,34$ Notably, molecular studies have associated higher mutation rates of the ATM gene, a genome integrity regulatory gene, with increased risk of CLL in men. ${ }^{7,35}$ In our setting, deletion 11q, which houses the ATM gene, were observed in only two women and two men. However, meaningful comparisons could not be made because of the small sample size. Therefore, we speculate that the observed gender discrepancies could be partly because of the well-documented reluctance of men to seek medical care $^{36,37}$ Nevertheless, there is a clear need for further investigations assessing the influence of gender on risk of CLL in SA.

The mean age at diagnosis at TAH was 66.79 years (Table 1) with a modal age range between 60 and 69 years (Table 1 and Figure 2). Concordant with our findings are observations previously made in $\mathrm{SA}_{,}{ }^{19}$ other African populations ${ }^{4,31,32}$ and some Western populations. ${ }^{8,33,38,39}$ In contrast, studies in
Zambia, Nigeria and Senegal have reported younger ages at presentation of CLL. ${ }^{18,19,26,29}$ Moreover, contrasting with our findings where men presented with CLL at a younger age than women, previous studies in Nigeria and Kenya showed women present with the disease at a younger age..$^{29,31}$ As such, a conclusion can be drawn that the ages at presentation of CLL by gender vary amongst different African countries.

\section{Human immunodeficiency virus status}

Of the 43 CLL patients who were tested for HIV, 93.02\% were negative for the virus. Similar low occurrences of concurrent HIV and CLL have been reported in other African populations. ${ }^{4,30,40,41}$ In this study, HIV-positive CLL patients were aged ranging from 43 to 50 years, which is considerably lower than the mean age of 66.79 years at CLL diagnosis in the overall cohort. Notably, the differences in the ages of risk for HIV, a disease of younger people ${ }^{42}$ and for CLL, a disease of older people, could be possible factors behind the uncommon overlap between the two diseases. ${ }^{43}$ In addition, all three patients had typical CLL morphologic and immunophenotypic features that were comparable to HIV-negative patients. Similarly, typical CLL immunophenotypic patterns have been reported elsewhere in patients with HIV, albeit with successful treatment for the virus. ${ }^{43}$ In our study cohort, however, it is unknown if patients were undergoing treatment for HIV or the length of time these patients had the infection. Furthermore, we are unaware whether HIV-positive patients in our cohort had the infection prior to the diagnosis of CLL or not. As a WHO gold standard, HIV testing is not a screening tool that forms part of the CLL diagnostic algorithm. ${ }^{9}$ However, HIV testing is conducted at our facility in all patients suspected of haematological malignancies because of the high prevalence of the virus in SA. In addition, the cytogenetic characteristics in HIV-positive patients followed no particular trend as they were different for all patients. Taken together, the similarities between CLL diagnostic features in patients with HIV and those without HIV suggest that the concurrency of the two diseases could have been coincidental.

\section{Cytogenetics}

Cytogenetic features at diagnosis of CLL provide prognostic indications that are important in planning for the management of the disease. ${ }^{44}$ The WHO generally recommends the assessment for genetic abnormalities for every CLL patient ${ }^{9}$; however, in a setting of low- and middle-income countries, cost factors, lack of skill capacity and infrastructure limit these kinds of assessments. Therefore, in our setting, cytogenetic investigations in the past were only performed for patients with inconclusive and/or atypical CLL morphology and/or immunophenotype, an aggressive disease course and first-line treatment resistant disease. Trisomy 12, a controversial indicator of intermediate prognosis, ${ }^{17}$ was the most common cytogenetic abnormality followed by deletion 13q14, an indicator of good prognosis ${ }^{17,45}$ (Table 1). Our observations are in contrast to the literature 
where deletion 13q14 is often a leading chromosomal aberration in about $50 \%$ of CLL patients ${ }^{45,46}$ followed by trisomy 12 in $15 \%-20 \%$ of the patients. ${ }^{17,45,47,48}$ Deletion $11 q 22$, which is associated with clinically progressive disease and a shorter time to first treatment, ${ }^{49}$ was the least common cytogenetic abnormality at our facility (Table 1). Its frequency fell within literature reported ranges of $5 \%-20 \%$ of patients. ${ }^{17,50}$ Two patients in our study had both trisomy 12 and deletion 11q22. One of these patients, an HIV-positive female aged 50 years, was treatment refractory with a progressive course of the disease. The second patient, an HIV-negative male, had no follow-up report and therefore, no further assessments were conducted. Furthermore, there were no deletions $17 \mathrm{p}$ in our study cohort and assessments for TP53 mutation status were not conducted on these patients as this is not routinely performed at our facility.

\section{Conclusion}

Our study showed an equal representation of men and women diagnosed with CLL at our facility. Men presented with the disease at a significantly younger age than women. Additionally, our findings suggest that HIV concurrent with CLL is uncommon in a high HIV prevalence setting. Demographic data of different cancer entities in the South African population are critical in geographical and population-specific risk assessments, prevention and management efforts of the cancer burden. In addition, these data are an important epidemiological tool that can be used to produce public health policies aimed at reducing new cancer cases and deaths. ${ }^{51}$ In SA, the NCR clusters cancer entities $^{52}$ despite their potential different treatment and overall management strategies. We therefore suggest updating the NCR of SA to include specific cancer entities, in a bid to closely monitor the occurrence of standalone cancers such as CLL and other haematological malignancies at a larger scale. Finally, we add knowledge to the prevalence of CLL in SA over a 6-year period and hopefully, this information will raise awareness on the need for entityspecific cancer demographic databases in SA and other African countries.

\section{Limitations of study}

No large-scale comparisons of CLL demographics and phenotypic features in SA were conducted because SA does not have entity-specific cancer registries. The unavailability of these entity-specific registries highlighted the need for the improvement of the South African cancer registries if it were to become a more effective tool in the local management of cancers. This information could have placed our study results into context, thereby potentially facilitating CLL management policy reviewing if required. In addition, the incidence rate of CLL was not determined because reliable data of the atrisk population size in our facility's catchment area were unavailable during our study. Another limitation was that the HIV data might have been under-represented, thus potentially influencing our findings, because testing is usually performed at the clinics that refer patients for hospital care. Routine hospital databases only had results for people tested on site and not for those coming from outside clinics. As such, because of the retrospective nature of this study, unmeasured factors could not be accounted for.

\section{Acknowledgements}

The authors would like to thank Mr W. Kleinhans from the IT department of the National Health Laboratory Service (NHLS) at TAH for technical data access and retrieval.

\section{Competing interests}

The authors declare that they have no financial or personal relationships that may have inappropriately influenced them in writing this article.

\section{Authors' contributions}

F.M. and C.C.S. contributed to the study design, data collection, analysis and interpretation. F.M. wrote the original manuscript. C.C.S., R.G. and A.A. conceptualised this study, provided supervision and revised this manuscript. F.M., R.G., A.A. and C.C.S. approved the final manuscript.

\section{Ethical considerations}

This study was approved by the Stellenbosch University, Faculty of Medicine and Health Sciences, Health Research Ethics Committee and the Western Cape Government of South Africa (ref. no. N07/03/068). This study forms part of the Tygerberg Lymphoma Study Group database (ref. no. S15/10/234) that was established in 2007 in the Division of Haematopathology, Department of Pathology, NHLS, TAH, to document all blood cancer cases presenting at TAH. Patient de-identified data collection was conducted to maintain the confidentiality of patients.

\section{Funding information}

This research did not receive any form of financial assistance from any funding agency.

\section{Data availability}

The data that support the findings of this study are available from the corresponding author, F.M., upon reasonable request.

\section{Disclaimer}

The views and opinions expressed in this article are solely of the authors and not necessarily representative of the official position or policy of affiliated entities of the authors.

\section{References}

1. Reed JC. Chronic lymphocytic leukemia: A disease of dysregulated programmed cell death. Clin Immunol Newsl. 1997;17(9):125-130. https://doi.org/10.1016/ s0197-1859(00)80016-3

2. Chiorazzi N, Rai KR, Ferrarini M. Chronic lymphocytic leukemia. N Engl J Med. 2005;24;352(8):804-815. https://doi.org/10.1056/nejmra041720 
3. Bosch F, Dalla-Favera R. Chronic lymphocytic leukaemia: From genetics to treatment. Nat Rev Clin Oncol. 2019:16(11):684-701. https://doi.org/10.1038/ s41571-019-0239-8

4. Salawu L, Bolarinwa RA, Durosinmi MA. Chronic lymphocytic leukaemia: A-twentyyears experience and problems in lle-Ife, South-Western Nigeria. Afr Health Sci. 2010;10(2):187-192.

5. Kipps TJ, Stevenson FK, Wu CJ, et al. Chronic lymphocytic leukaemia. Nat Rev Dis Prim. 2017;3(1). https://doi.org/10.1038/nrdp.2016.96

6. Redaelli A, Laskin BL, Stephens JM, et al. The clinical and epidemiological burden of chronic lymphocytic leukaemia. Eur J Cancer Care (Engl). 2004;13(3):279-287. https://doi.org/10.1111/j.1365-2354.2004.00489.x

7. Cantú ES, McGill JR, Stephenson CF, et al. Male-to-female sex ratios of abnormalities detected by fluorescence in situ hybridization in a population of chronic lymphocytic leukemia patients. Hematol Rep. 2013;5(1):13. https://doi. org/10.4081/hr.2013.e4

8. Abrisqueta $P$, Pereira A, Rozman $C$, et al. Improving survival in patients with chronic lymphocytic leukemia (1980-2008): The Hospital Clínic of Barcelona experience. Blood. 2009;114(10):2044-2050. https://doi.org/10.1182/ blood-2009-04-214346

9. Swerdlow SH, Campo E, Harris NL, et al., editors. WHO classification of tumours. Tumours of haematopoietic and lymphoid tissues. Rev 4th ed. Lyon: IARC, 2017; p. 216-221.

10. Inamdar KV, Bueso-Ramos CE. Pathology of chronic lymphocytic leukemia: An update. Ann Diagn Pathol. 2007;11(5):363-389. https://doi.org/10.1016/j. anndiagpath.2007.08.002

11. Hallek M, Cheson BD, Catovsky D, et al. Guidelines for the diagnosis and treatment of chronic lymphocytic leukemia: A report from the International workshop on chronic lymphocytic leukemia updating the National Cancer Institute-Working Group 1996 guidelines. Blood. 2008;111(12):5446-5456. https://doi. org/10.1182/blood-2007-06-093906

12. Matutes E, Polliack A. Morphological and immunophenotypic features of chronic lymphocytic leukemia. Rev Clin Exp Hematol. 2000;4(1):22-47. https://doi. org/10.1046/j.1468-0734.2000.00002.x

13. Hsi ED. Pathologic and molecular genetic features of chronic lymphocytic leukemia. Semin Oncol. 2012;39(1):74-79. https://doi.org/10.1053/j. seminoncol.2011.11.007

14. Scarfò L, Ferreri AJM, Ghia P. Chronic lymphocytic leukaemia. Crit Rev Oncol Hematol. 2016;104(3):169-182. https://doi.org/10.1016/j.critrevonc.2016.06.003

15. Moreau EJ, Matutes E, A'hern RP, et al. Improvement of the chronic lymphocytic leukemia scoring system with the monoclonal antibody SN8 (CD79b). Am J Clin Pathol. 1997;108(4):378-382. https://doi.org/10.1093/ajcp/108.4.378

16. Hallek M. Chronic lymphocytic leukemia: 2015 update on diagnosis, risk stratification, and treatment. Am J Hematol. 2015;90(5):446-460. https://doi. org/10.1002/ajh.23979

17. Döhner H, Stilgenbauer S, Benner A, et al. Genomic aberrations and survival in chronic lymphocytic leukemia. New England Journal of Medicine. 2000;343(26):1910-1916. https://doi.org/10.1056/nejm200012283432602

18. Sall $A$, Fall $S$, Sène $A$, et al. Characteristics of chronic lymphocytic leukemia in Senegal. BMC Hematol. 2016;16(1):4-11. https://doi.org/10.1186/s12878-0160051-y

19. Nel T, Joubert G, Van der Ryst $E$, et al. Chronic lymphocytic leukaemia in the Bloemfontein academic hospitals. Cent Afr J Med. 1998;44(8):195-199.

20. Omoti CE, Awodu OA, Bazuaye GN. Chronic lymphoid leukaemia: Clinicohaematological correlation and outcome in a single institution in Niger Delta region of Nigeria. Int J Lab Hematol. 2007;29(6):426-432. https://doi. org/10.1111/j.1751-553x.2007.00888.x

21. Lehohla P. Statistical release P0302: Mid-year population estimates 2016. Pretoria: Statistics South Africa, 2016; p. 1-17.

22. Western Cape Government. Tygerberg Hospital: Overview | Western Cape Government [homepage on the Internet]. 2017 [updated 2016 Oct 28. cited 2020 Nov 22]. Available from: https://www.westerncape.gov.za/your_gov/153

23. Abayomi EA, Somers A, Grewal R, et al. Impact of the HIV epidemic and antiretroviral treatment policy on lymphoma incidence and subtypes seen in the Western Cape of South Africa, 2002-2009: Preliminary findings of the Tygerberg Lymphoma Study Group. Transfus Apher Sci. 2011;44(2):161-166. https://doi. org/10.1016/j.transci.2011.01.007

24. Swerdlow S, Campo E, Harris N, et al. WHO classification of tumours of haematopoietic and lymphoid tissues. 4th ed. Lyon: IARC; 2008.

25. Dong $Y$, Shi $O$, Zeng $Q$, et al. Leukemia incidence trends at the global, regional, and national level between 1990 and 2017. Exp Hematol Oncol. 2020;9(14):1-11. https://doi.org/10.1186/s40164-020-00170-6

26. Fleming $A F$, Terunuma $H$, Tembo $C$, et al. Leukaemias in Zambia. Leukemia. 1999;13(8):1292-1293. https://doi.org/10.1038/sj.leu.2401473

27. Omoti CE, Imiere EO. Trends in the pattern of leukaemia incidence in a tertiary health center in Nigeria: 1990-2004. J Med Biomed Res. 2006;5(2):44-49. https:// doi.org/10.4314/jmbr.v5i2.10692

28. Omoti CE, Nwannadi Al, Obieche JC, et al. The epidemiological features of lymphoid malignancies in Benin City, Nigeria: A 15 years study. Pan Afr Med J. 2012;11:10.
29. Errahhali ME, Errahhali ME, Boulouiz R, et al. Distribution and features of hematological malignancies in Eastern Morocco: A retrospective multicenter study over 5 years. BMC Cancer. 2016;16(1):1-10. https://doi.org/10.1186/ study over 5 years.
s12885-016-2205-5

30. Mukiibi JM, Paul B, Nyirenda CM, et al. Chronic Lymphocytic Leukaemia (CLL) in Central Africans. Cent Afr J Med. 2004;50(11/12):111-115.

31. Mulwa-Babu E, Paresh D, Riyat M. Chronic lymphocytic leukemia in Kenya: An immunophenotypic and clinicopathologic study. J Africain du Cancer. 2013;5(4):192-197. https://doi.org/10.1007/s12558-013-0288-3

32. Dali N, Ait Ali $\mathrm{H}$, Tibiche A, et al. Epidemiology and clinical features of chronic lymphoid leukemia. Review of the Algerian Chronic Lymphoid Leukemia Study Group. Blood. 2015;126(23):5274-5274. https://doi.org/10.1182/blood v126.23.5274.5274

33. Cancer Research UK. Chronic lymphocytic leukaemia (CLL) statistics | Cancer Research UK [homepage on the Internet]. 2017. [updated 2021 Feb 02; cited 2020 Dec 29]. Available from: https://www.cancerresearchuk.org/health-professional/ cancer-statistics/statistics-by-cancer-type/leukaemia-cll

34. Siegel RL, Miller KD, Jemal A. Cancer statistics, 2017. CA Cancer J Clin. 2017;67(1):7-30. https://doi.org/10.3322/caac.21387

35. Guarini A, Marinelli M, Tavolaro S, et al. ATM gene alterations in chronic lymphocytic leukemia patients induce a distinct gene expression profile and predict disease progression. Haematologica. 2012;97(1):47-55. https://doi. predict disease progression. Haem
org/10.3324/haematol.2011.049270

36. Galdas PM, Cheater F, Marshall P. Men and health help-seeking behaviour: Literature review. J Adv Nurs. 2005;49(6):616-623. https://doi. Literature review. Adv Nurs.
org/10.1111/j.1365-2648.2004.03331.x

37. Lehohla P. Use of health facilities and levels of selected health conditions in South Africa: Findings from the General Household Survey, 2011. Pretoria: Statistics South Africa, 2013; p. 1-81.

38. National Cancer Institute. Chronic lymphocytic leukemia - SEER stat fact sheets [homepage on the Internet]. 2019 [updated 2020 Sep 14; cited 2020 Nov 15] Available from: https://seer.cancer.gov/statfacts/html/clyl.htm

39. Parikh SA, Rabe KG, Kay NE, et al. Chronic lymphocytic leukemia in young $1 \leq 55$ years) patients: A comprehensive analysis of prognostic factors and outcomes. Haematologica. 2014;99(1):140-147. https://doi.org/10.3324/haematol.2013. 086066

40. Shimada N, Yuji K, Ohno N, et al. Treatment of chronic lymphocytic leukemia with bendamustine in an HIV-infected patient on antiretroviral therapy: A case report and review of the literature. Clin Case Reports. 2015;3(6):453-460. https://doi. org/10.1002/ccr3.244

41. Cole J, Pantanowitz L, Aboulafia D. Human immunodeficiency virus and chronic lymphocytic leukemia. Leuk Lymphoma. 2009;50(11):1885-1888. https://doi. org/10.3109/10428190903216820

42. Simbayi L, Zuma K, Zungu N, et al. South African National HIV prevalence, incidence, behaviour and communication survey, 2017: Towards achieving the UNAIDS 90-90-90 targets. Cape Town; HSRC Press; 2019.

43. Ravandi F, Verma A, Ridgeway J, Pursell K. Chronic lymphocytic leukemia (B-CLL) occurring with human immunodeficiency virus (HIV) infection: Implications. Leuk Res. 2003;27(9):853-857. https://doi.org/10.1016/s01452126(03)00004-3

44. Hallek M. Signaling the end of chronic lymphocytic leukemia: New frontline treatment strategies. Blood. 2013;122(23):3723-3734. https://doi.org/10.1182/ blood-2013-05-498287

45. Puiggros A, Blanco G, Espinet B. Genetic abnormalities in chronic lymphocytic leukemia: Where we are and where we go. Biomed Res Int. 2014;2014.1-13. https://doi.org/10.1155/2014/435983

46. Kiefer $Y$, Schulte $C$, Tiemann $M$, et al. Chronic lymphocytic leukemia-associated chromosomal abnormalities and miRNA deregulation. Appl Clin Genet. 2012;5:21-28. https://doi.org/10.2147/tacg.s18669

47. Döhner $H$, Stilgenbauer $S$, James MR, et al. 11q deletions identify a new subset of B-cell chronic lymphocytic leukemia characterized by extensive nodal involvement and inferior prognosis. Blood. 1997;89(7):2516-2522. https://doi.org/10.1182/ blood.v89.7.2516

48. Bulian P, Bomben R, Dal Bo M, et al. Mutational status of IGHV is the most reliable prognostic marker in trisomy 12 chronic lymphocytic leukemia. Haematologica. 2017;102(11):e443-e446. https://doi.org/10.3324/haematol.2017.170340

49. Wierda WG, O'Brien $S$, Wang $X$, et al. Multivariable model for time to first treatment in patients with chronic lymphocytic leukemia. J Clin Oncol. 2011;29(31):4088-4095. https://doi.org/10.1200/jco.2010.33.9002

50. Marasca R, Maffei R, Martinelli S, et al. Clinical heterogeneity of de novo 11q deletion chronic lymphocytic leukaemia: Prognostic relevance of extent of $11 \mathrm{q}$ deleted nuclei inside leukemic clone. Hematol Oncol. 2013;31(2):88-95. https:// doi.org/10.1002/hon.2028

51. Bouchardy C, Rapiti E, Benhamou S. Cancer registries can provide evidence-based data to improve quality of care and prevent cancer deaths. Ecancermedicalscience. 2014;8:413. https://doi.org/10.3332\%2Fecancer.2014.413

52. NICD. National Cancer Registry I NICD. National Institute for Communicable Diseases [homepage on the Internet]. 2018 [updated 2020 Aug; cited 2020 Nov 22]. Available from: https://www.nicd.ac.za/centres/national-cancerregistry/ 